Maury, M. (France), asked whether in the monotubular caliper there was not a contra-indication when there was adduction and flexion spasm at the knees.

Dollfus, $P$., replied that they had not had any problems with flexion and adduction spasm at the knee. They had seen only patients with a tendency to flexion spasms at the knee, and the new design was as strong and equivalent to the conventional type of caliper in that respect.

Maury, $M$. (France), asked about the knee bending automatic device, which in this particular caliper was short.

Dollfus, $P$. agreed. There were different types on normal classical calipers-the Hoffer system or Swiss system-and when a person sat down the flexion of the caliper bent automatically at the knee hinge to allow the patient to sit. In this caliper, which they were actually trying on him, they thought they would adopt a $\frac{1}{2}$ Hoffer system to be able to catch the angle of the chair or seat so that automatically the caliper would bend in two at the hinge.

\title{
RESPIRATORY AND OTHER DEVICES FOR THE TOTALLY PARALYSED IN DOMICILIARY LIFE
}

\author{
By Dr. Margaret Agerholm, M.A., B.M., B.Ch. Oxon. \\ Nuffield Department of Orthopaedic Surgery, University of Oxford, England
}

\section{SUMMARY}

Permanent dependence on a mechanical respirator, even when associated with severe or total locomotor paralysis, does not preclude discharge from hospital to domiciliary life, provided certain equipment and facilities are provided. Much can be learnt from cases of lower motor neuron paralysis of the respiratory musclesusually caused by poliomyelitis and associated with severe locomotor disabilitywho have successfully established themselves at home and, step by step, overcome the difficulties created by their respiratory and locomotor paralyses.

The equipment and facilities which they need fall into three categories:

(a) Respiratory. They need not only the necessary basic equipment of respirator and, where necessary, sucker, but also a reliable system to ensure that errors in electricity supply, in the machines themselves, and in the connections and other accessories are easily, promptly and, if possible, automatically corrected. Provision should also be made for mobility of the patient and his equipment, so that he is not permanently confined to one room in one house. Adequate arrangements must be made for servicing the equipment at regular intervals and for rectifying faults.

(b) 'Care'. Wise selection of equipment and techniques for routine nursing and daily living activities greatly reduces the time and effort spent on them.

(c) Occupational and Recreational. These enable the patient and his family to live to maximum capacity within the limits of the physical disability: they may enable the patient himself to earn part or all of the necessary family income.

The importance of this final stage of rehabilitation in the management of the severely paralysed is stressed. 


\title{
Discussion
}

Dollfus, $P$. (France), asked Dr. Agerholm whether, amongst the I5 deaths, she had a case of acute respiratory exhaustion during sleep. He remembered a polio patient in Copenhagen with a complete paralysis of the upper limbs, who went home and led a nearly completely normal life and suddenly one night she died. She obviously had not represented any symptoms of hypoventilation or respiratory distress, and actually to his knowledge this happened in Copenhagen twice.

Agerholm, M., said she had not seen this at all, and of course this series did not apply to people who were weaned completely - but she had not done so in other circumstances. Two of the people were found dead in the morning while their curasses were working. Both were elderly patients, and she thought the limit of life for these people was probably somewhere around the 50 mark. In neither of them did a P.M. show any reason for the death, apart from the fact that one wondered why they were alive for other reasons.

Frankel, H. L. (England), would like to agree with Dr. Agerholm on the need to hyperventilate patients on respirators. They had constantly exceeded the norms in the published books by about roo per cent. over the last few years and the patients seemed to do very well on it. He would agree that while on a respirator the patient was always right but he wondered whether Dr. Agerholm had anything to say about whether the patient was also always right when he or she had been weaned from the respirator.

Agerholm, M., replied that, yes, she did still feel the patient was always right except in the sense that he should have rather more aid than perhaps he was trying to manage to do without. She once got herself into a very difficult situation by criticizing at a physiotherapy meeting the way they weaned a patient on 'Emergency Ward Io' in which patients were encouraged and forced to breathe rather longer than they wanted to! But she did very much believe that the patient was the best judge, given the guidance, and that one must never press people to do without apparatus unless one's slant was that one should insist on their using apparatus when they did not want to. This she thought one occasionally had to do because patients got a bit bloody-minded when hypoventilated.

\section{RESPIRATORY AND METABOLIC MANAGEMENT IN ACUTE TETRAPLEGIA}

\author{
By D. J. E. Cheshire, M.B., B.S., D.Phys.Med., and D. A. Coats, M.B., B.S. \\ Spinal Injuries Centre, Austin Hospital, Heidelberg, Victoria, Australia, and The Department \\ of Physiology, University of Melbourne
}

THE management of the respiratory problems of acute traumatic tetraplegia has been discussed in previous papers. This paper presents a modification and extension of the same subject and, in addition, attempts to correlate the respiratory and metabolic facets of management into a pattern of treatment which will maintain adequate alveolar ventilation and nutrition and a normal fluid and electrolyte balance.

The maintenance of adequate alveolar ventilation may be threatened by:

I. Increasing paralysis of the muscles of respiration.

2. The supervention of either pulmonary consolidation or collapse. These complications are related to the aspiration of vomitus, the inability to deliver sputum to the mouth, and the inspissation of sputum.

3. Pulmonary oedema, due to overhydration of the patient. 